\title{
A luta dos aposentados
}

Luis Firmino de Lima, 68 anos, casado, operário têxtil aposentado. Nesta condição de aposentado, vive uma situação semelhante a da maioria das pessoas idosas no país. Ele nos deu um depoimento sobre a sua vida e sobre a situação dos aposentados boje:

"Sou um filho do Norte. Nasci na cidade de Paulista, em Pernambuco. Comecei a trabalhar com seis anos de idade: carregava frete na feira e vendia frutas para ajudar os meus pais. Com nove anos trabalhava como contínuo num escritório. Depois aprendi a trabalhar com o tear. Emigrei para o Recife e fui trabalhar como tecelão.

Em 1949, emigrei para São Paulo esperando que a minha situação melhorasse. Naquela ćpoca, havia muita falta de mão-de-obra; cheguei num dia e comecei a trabalhar no outro. Em 1951, passei a participar na luta dentro do Sindicato. Participei muito de passeatas, de greves, de congressos etc.

Eu não tenho estudo, tenho só o curso primário incompleto. A minha universidade foi a vida, no dia-a-dia. $O$ que tenho de posse hoje é uma casinha para morar e um carnê da Previdência Social.

O idoso é uma camada desamparada, especialmente os que se aposentam como trabalhador assalariado. Ele já produziu o máximo de sua capacidade e por isso deveria ter todo o amparo da sociedade com direito a lazer, moradia, alimentação, trans" porte etc. Ao se aposentar, é justamente quando a pessoa mais precisa de bem-estar, Ao invés disso, torna-se um castigo.

Somos 11 milhões de aposentados e pensionistas no país. Desse total, $70 \%$ ganham menos de um sálario mí-

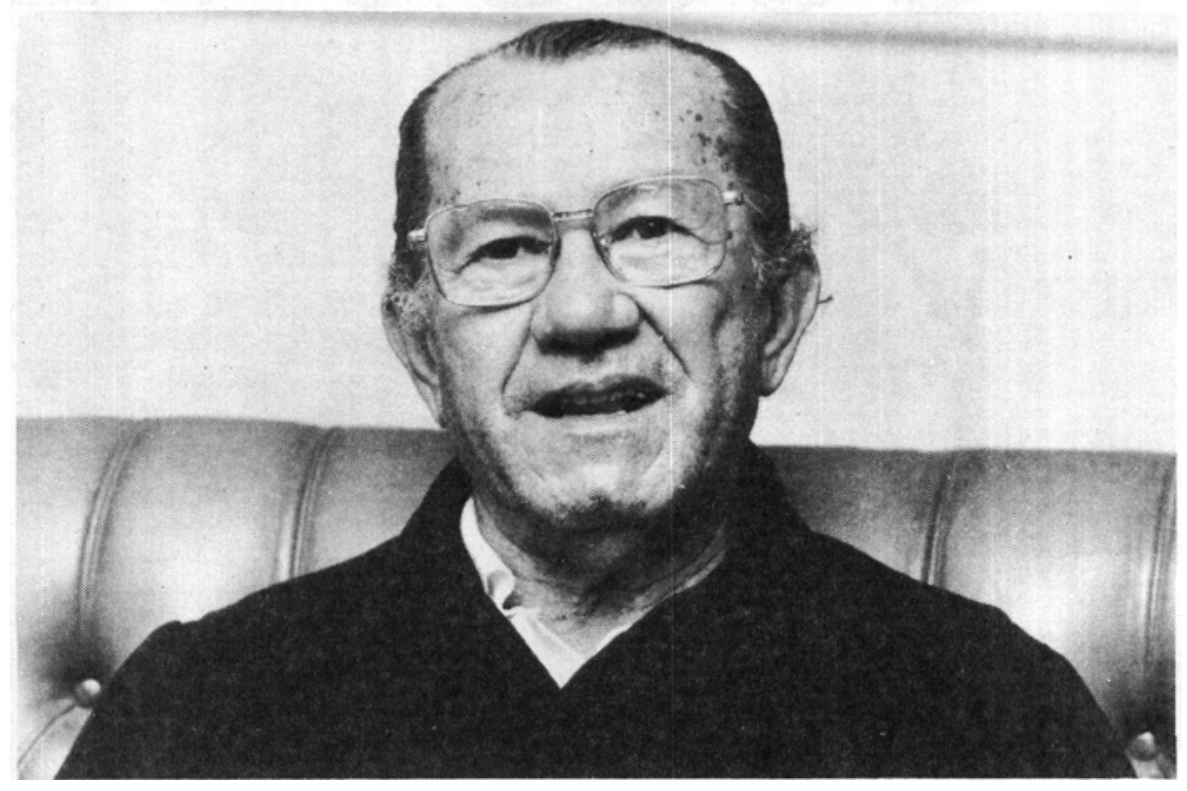

Luis Firmino de Lime

nimo. Até parece um contraste com as riquezas que o Brasil possui, pois a maioria do povo passa fome. Se essas riquezas fossem distribuídas equitativamente para o seu povo, o brasileiro viveria uma média de 75 anos aproximadamente. Não é o que acontece hoje, pois quem chega vivo à aposentadoria já está envelhecido precocemente.

Antes de 1964, a maioria dos trabalhadores recebia a aposentadoria com base na média dos últimos 12 meses, o que na prática significava que ele continuava recebendo na aposentadoria o salário integral que recebia antes. Depois do chamado golpe de 1964, a média de cálculo da aposentadoria passou de 12 para 24 meses. Atualmente a base desse cálculo são os últimos 36 meses. Isso quer dizer que o salário da aposentadoria caiu por volta de 60 a $65 \%$ em relação ao salário anterior à aposentadoria. Por isso os proventos dos aposentados hoje são baixíssimos. Nestes úl- timos vinte anos, a camada dos aposentados foi a mais sacrificada entre os trabalhadores.

Até 1979 , os reajustes que vinham para os aposentados eram calculados na base do salário mínimo. $O$ que fez o governo de então? Quando houve o reajuste do salário mínimo de 300 para 600 cruzeiros, o reajuste dos aposentados continuou sendo calculado na base de 300 e não de 600 cruzeiros. Assim, o salário do aposentado foi caindo a cada ano que se passou. Por exemplo, as pessoas que se aposentaram ganhando um salário mínimo naquela época, hoje estão ganhando menos de $1 / 6$ do salário mínimo. Tem gente com 65 ou 68 anos que ganha na base de cem ou cento $e$ vinte cruzados. Quer dizer que mal dá para comprar um pouco de arroz e feijão. Assim dá para calcular como vive essa gente.

Muitos aposentados conseguem sobreviver porque têm os seus filhos e netos que os ajudam. Aqueles que não 
têm familiares precisam fazer algum bico para sobreviver. $E$ aqueles que nāo podem fazer 'bico' morrem à míngua, porque nāo conseguem pagar aluguel de casa nem obter alimentação. Estes vivem jogados nos jardins, nos botecos, acabando com o restinho de suas vidas desconsoladas porque não têm mais condições de viver dignamente. Ficam zanzando por aí, pensando nessa vida, e é um pensamento negativo que leva à liquidação da vida destes idosos. As autoridades deveriam procurar, pelo menos, minimizar o sofrimento dos idosos, especialmente os que estão aposentados, garantindo o salário mínimo integral para não morrerem de fome.

$\mathrm{Na}$ família existem problemas muito sérios que de fato marcam muito os idosos. Existem pessoas que eu cotheço e que depois da aposentadoria não têm mais dinheiro para manter a família como mantinha antes. Os fiIhos começam a achar ruim e alguns chegam até a dizer:- ' $O$ senhor está comendo às minhas custas', É claro que não são todos os que pensam e agem assim, mas muita gente vê o idoso como uma pessoa imprestável, um trapo, enfim, tacham de tudo o que não presta.

$\mathrm{Na}$ minha família, precisei fazer 'bico'quando me aposentei para manter o mesmo salário que recebia antes da aposentadoria. Naquela altura, os meus filhos já foram se casando e então não deu maiores problemas. Isso talvez porque soube preparar o espírito dos meus filhos para receber aquilo que eu era ou ia ser na velhice.

Hoje não fico muito tempo em casa durante o dia para não aborrecer muito a minha esposa. E um proble- ma sério a vida cotidiana do casal, quando chega a uma certa idade. $O$ meu esporte é andar: muitas vezes fico andando pelas ruas da cidade durante um bom tempo. Outra coisa que faço muito hoje é ler. A leitura é o meu ponto fraco. Uma vez encontrei uma senhora com 88 anos, sentada num banco de jardim, lendo com muito interesse. Aproximei-me dela e perguntei:por que ela com aquela idade lia tanto? Ela respondeu: 'Meu filho, o saber nunca é pouco e não tem idade para se aprender.' Eu concordo com ela.

Passo a maior parte do meu tempo no Centro de Memória Sindical, no Sindicato dos Têxteis, e continuo na luta defendendo os aposentados. Vou fazer 68 anos e ainda estou com espírito de jovem, porque estou na luta com os meus companheiros."
Devido ao grande avanço tecnológico da sociedade moderna, tivemos a oportunidade de constatar uma série de contradiçōes intrínsecas ao próprio sistema sem thes creditar, no entanto, o justo valor.

Nesta suscinta elaboração de idéias, acreditamos nāo ser necessário apresentarmos o lado positivo de nosso objeto de análise, mas dedicarmos um pouco da nossa atençāo aos efeitos danosos que já assumjram um vulto suficientemente perverso para a própria sobrevivência digna do ser humano.

Muitos daqueles que lerem nosso enfoque dirão que fazemos a apologia do "velho" - um grupo tão minoritário quanto o negro, homossexual - e questionarão a validade do mesmo. Não negamos esta perti- nente colocação, só gostaríamos de ressaltar que o "velho" é um dos muitos que sofrem discriminação, mas ao mesmo tempo único por excelência: somente este engloba todos os outros num determinado momento de nossas vidas.

\section{Qual o objetivo último da vida?}

Engajados na luta do dia-a-dia, na tentativa de sobrevivermos num ritmo que se nos impõe cada vez mais alucinante, fomos pouco a pouco nos esquecendo de nossa "vida". Aparentemente contraditória, esta afirmação se faz clara quando tentamos defini-la: "Num infinitezimal espaço de tempo que nosso corpo tenta preencher e atingir a felicidade, batalhamos para conseguir aquilo que subliminarmente nos é ensinado $e$, tão bem feito e gradativo foi este processo que o consideramos natural, ou pior, nem ao menos nos detemos mais para perguntar: mas, qual é o objetivo último?"

Nossos valores foram paulatinamente sendo modificados para se coadunarem com esta nova ideologia. A "falta de tempo" para obter e conseguir gozar tudo que nos é ofertado, nos deixou angustiados e sem espaço para que nos detivéssemos e analisássemos com um pouco mais de zelo o que tal mudança nos traria no futuro que se faz presente.

\section{A metáfora da nossa época}

Sem qualquer intenção de nos apresentarmos irônicos, acreditamos que nenhuma outra metáfora simboliza melhor a "doença da nos- 